\title{
The Self-Flipped Classroom Concept: Underlying Ideas and Experiences
}

\author{
Anna Vasilchenko \\ Open Lab \\ Newcastle University \\ Newcastle, UK \\ a.vasilchenko@ncl.ac.uk
}

\author{
Åsa Cajander, Mats Daniels \\ Department of Information Technology \\ Uppsala University \\ Uppsala, Sweden \\ asa.cajander@it.uu.se, matsd@it.uu.se
}

\author{
Madeline Balaam \\ Department of Media Technology and \\ Interaction Design \\ KTH Royal Institute of Technology \\ Stockholm, Sweden \\ balaam@kth.se
}

\begin{abstract}
In the modern fast changing world no formal education is able to provide learners with a complete set of knowledge, skills and competences that they would need to successfully compete on tomorrow's job market. Therefore, the role of universities is increasingly shifting towards provision of an environment where students have a chance to acquire lifelong learning skills. This paper presents underlying ideas of, and practical experiences with, an innovative pedagogy that addresses the lifelong learning skills acquisition along with additional benefits for science and technology students. The proposed approach, called self-flipped classroom (SFC), is built on a synergy of two pedagogies: learning through making and flipped classroom. To unveil the construct of the SFC, we discuss each of its components individually presenting appropriate theoretical grounding. We also report on our experiences from self-flipped classroom implementations in two countries, UK and Sweden, and in three different educational settings. From our work with the SFC concept we have identified four different roles the students can assume in a SFC scenario: creators, collaborators, communicators, and learners. We present our observations regarding the identified roles that have been found in the studied settings. We also outline some implications for teaching using the SFC concept and future research directions in this space.
\end{abstract}

Keywords - Student-centered learning, learning through making, constructionism, student-generated content, flipped classroom, self-flipped classroom, computing science education, higher education

\section{INTRODUCTION}

Information and communication technologies have become a crucial part of all aspects of modern life. The complexity of computing systems is rapidly growing and higher education struggles with covering all knowledge required to work with computing systems today and in the future. Therefore, today's students need to practice lifelong learning skills and develop strategies for informal learning. It is often overlooked, however, that these lifelong learning skills need to include not only knowledge consumption, i.e. effective learning from others, but also knowledge production, i.e. creating material for others to learn from. These lifelong learning skills are critical for societal development. In this paper we present underlying ideas of, and experiences with, an innovative pedagogy for lifelong learning skills building on the concepts of flipped classroom and learner-generated content.

The flipped classroom concept [1] has become a key idea when it comes to activating students. The principle is that the course material is delivered to students in the form of audiovideo recordings and reading materials via digital and online media, so students prepare for class in advance by studying the material outside of class time at their own pace, and then in class they do 'homework' by solving problems together with the teacher and other students. This is often coupled with a test before the class time, which informs the teacher on what has been problematic for the students. In the self-flipped classroom (SFC) concept, the material to be learned is generated by the students, which takes the activation of students a step further. It also provides a format where the learning can be geared towards a student-centered pedagogy [2]. The SFC concept is adaptable in character and can be well-suited to many educational settings. Essential for using the concept, independently of educational settings, is to understand student roles and behaviors.

The self-flipped classroom (SFC) concept has been developed as a product of work aimed at studying innovative methods of teaching and learning for STEM subjects in Higher Education at Newcastle University, UK [3]. The main goal was to develop a distinctive educational approach which was based on a synergy of two pedagogies: flipped classroom and learning through making. The motivation for this research was based on the popularity of flipped classroom along with the advocacy for various types of active learning, such as peer learning and learning through making, in particular. To unveil the construct of the SFC concept, we will discuss its components individually: the "self" part stands for the student-generated content and learning through making, whereas the "flip" part stands for the flipped classroom in general.

In this paper we will report on experiences from SFC implementations in two countries, UK and Sweden, and in three educational settings, so as to elaborate on student behavior and experiences of SFC educational settings. These represent different settings, and observations regarding challenges and opportunities are presented. Moreover, from our work with the SFC concept we have identified four different roles the students can assume in an SFC scenario. These roles are: creators, collaborators, communicators, and learners. We will look into these roles from the perspective of a theoretical framework of constructionism [4] and also place the SFC concept in the context of other student-centered theories of learning. Central in this is the idea of learning through making [5], which will be highlighted in the paper.

This paper is structured in the following way. We start by defining the self-flipped concept, followed by a description of the theoretical background including constructivism and constructionism, the flipped classroom concept, contributing student pedagogy, and learning through making. We then move on to describing the educational settings in the two 
countries and the methods for data collection we used to investigate student attitude and behavior with regards to SFC. We then present our findings and relate them to the identified student roles in section V. Afterward, we outline some implications related to teaching using the SFC concept in section VI, future work is given in section VII, following with the conclusion in section VIII.

\section{THEORETICAL BACKGROUND}

In this section we present some underlying ideas, and central theories of learning relevant for the self-flipped classroom concept.

\section{A. Constructivism and Constructionism}

Many modern pedagogical approaches, including flipped classroom, ground themselves, at least partially, on the cognitive theory of constructivism. The theory developed by Jean Piaget in 1960s [6] advocates that knowledge is actively constructed by a learner through the contact with the world. This theory mostly focuses on individual knowledge construction, where meaning is discovered and formed into unique structures which continually evolve through the interaction with other people and with things [7]. This perfectly suits a part of SFC concept when the focus is on inclass active learning activities. However, constructivism does not cover the 'making' part of the SFC approach. Which is, therefore, better informed by a close relative of Piagetian theory - the learning theory of constructionism, developed by Papert in 1987.

Seymour Papert, who was a student of Piaget, expanded on constructivism to describe constructionism in terms of helping the student as part of their learning to produce constructions that others can see and critique. Papert explored how learners engage in a conversation with their own or other people's physical constructions (=artifacts), and how these conversations encourage self-directed learning, and as the result enable the construction of new knowledge [4].

We see the following four features of constructionism particularly suited for application to the SFC concept:

1) Learning through making - the core of both (the theory and the approach) is creation of a meaningful artifact through or because of learning activities;

2) Public entity - the constructionist artifacts are designed and created to be visible and accessible to others, which very well translates to the SFC concept where the artifacts are used by other students for their own learning;

3) Instruction - constructionist instruction implies interaction between the teacher and the student during the process of design, discussion and creation of learning artifacts which have social relevance; this translates to emphasizing the teacher's role in SFC pedagogy as a facilitator of active learning activities particularly those which result in artifact creation;

4) Technology - another important component of constructionism is the use of technological tools for facilitation of learning processes; in SFC concept there is an emphasis on technology which not only supports blended learning (as in flipped classroom), but also facilitates the production of different artifacts.
Constructionism has been criticized for being just a "metatheory" and not explicit enough on how the learning occurs. Hoban et al [8], for example, argues that while highlighting the importance of the interaction between personal and social knowledge construction and its influence on learning, constructionism does not help to articulate and understand the process of designing and making artifacts. Therefore, it does not justify why this process is valuable for the learning itself. Kafai [9] at the same time explains the constructionist process of knowledge construction through appropriation. She cites Papert, arguing that physical objects play a central role in the knowledge construction process as "learners make knowledge their own and begin to identify with it" [9] when they transform that knowledge into a physical artifact.

\section{B. Learning Through Making}

Among the four presented features of constructionism, the "learning through making" part is the most significant for the SFC concept. We therefore discuss this part in more detail and, together with the other three features, relate it further to the SFC. In that way, we are developing a notion of learning through making a public entity with the right support from the instructor and the use of currently available technology.

Learning through making is a popular concept which could be applied to a wide range of educational settings. While recently it has received a particular attention in regards to the informal (out of school) STEM learning [10], in this work, we focus on formal educational settings such as universities.

In the SFC setting, the constructionist "public entity" feature translates into the artifact created to be used for peer assisted learning. As mentioned before, the student-created artifacts are reviewed and discussed by other students (=peers) in the presence and with the help of the teacher. In general, student contribution to peer assisted learning can vary greatly, being as little as participation in a class discussion or as substantial as facilitating a seminar or developing materials to cover a topic. In this work we are focusing on contributions that involve tangible (though mostly digital) artifact creation. In order to be sustainable, the SFC concept requires not-perishable and reusable artifacts which can "live" without their creators.

Easily available personal digital technologies nowadays offer increasing opportunities for students in schools and universities to learn through making of their own digital artifacts. Yet it has been argued that students use technology more creatively and efficiently outside of the education system than they do within classrooms [11]. Multiple studies suggested that schools should make use of learners' passion for technology and their naturally developed media literacy to enhance their learning experience. The development of Web 2.0 technologies, which are characterized as those that emphasize user-generated content along with user interaction and collaboration [12], power a growing trend: yesterday's audience increasingly become content creators and communicators [13]. "Producing, commenting, and classifying are just as important as the more passive tasks of searching, reading, watching, and listening" [14, p. 9].

Instructors have been asking students to create class content (for example in the form of multiple-choice questions) to build interaction and support excitement in the classroom back in 1980's [15], long before Web 2.0. 
However, with an abundance of technological tools available today we see more studies demonstrating learning improvements for students who engage in content creation [11], [16]. In addition to multiple-choice questions, examples of student-generated content effectively introduced into the curriculum, include editable wiki-pages [13], narrated animations [8], video vignettes [17], digital games [18] and video tutorials [19].

Further studies suggest that students who are engaged in the creation of digital artifacts demonstrate a higher level of thinking and deeper learning which then leads to improved academic performance, as argued by Bates et al [20], [21], Hardy et al [22] and Wheeler et al [13].

In addition to linking the creation of digital products with deeper learning of the subject evidence suggests other benefits, such as: i) multi-media production helps students to better engage with the subject and to look at the material under a different angle [8]; ii) it stimulates the development of creativity and critical thinking skills [12]; iii) finally, produced materials become tangible objects for student learning portfolios [12].

\section{Contributing Student Pedagogy}

A relevant (in the context of SFC) mix of learning through making and peer learning concepts was introduced by Collis and Moonen in 2005 as contributing student pedagogy (CSP) [23]. This concept emphasizes the process of learning by engaging students as co-creators of learning resources. The notion then has been further researched and developed in several works by Hamer et al, for example [24], [25]. The principles of CSP originate from constructivist [26] and sociocultural constructivist [27] cognitive theories, and the theories of knowledge sharing and development through communities of practice [28].

CSP is defined by the following two features [25]:

- Students contribute to the learning of others. These contributions may take a variety of forms, such as creating tutorial materials, demonstrations, worked examples, examination questions, etc.

- Students value the contributions of others. The students believe that the contributions of others are potentially useful in the context of the course.

The core element of CSP is the explicit creation of tangible, identifiable artifacts by one or more students for the purpose of being used by other students for their own learning. Hamer et al [24] differentiate student artifacts useful for CSP from those which are not rich enough to explicitly be used by other students for learning, e.g. "the use of 'clickers' in lectures where the 'artifact' created by students is a numerical answer to a multiple choice question"; and those which are created solely for the teacher (as part of an assessed exercise) and not reusable in a broader than just exemplary way [24]. This definition of learning artifacts echoes requirements of self-flip materials to be substantial and reusable.

Hamer et al [25] conducted a comprehensive literature survey of CSP studies with particular interest in computer science education. The survey resulted in several case studies with description of a range of CSP environments (working alone, in pairs or in small groups), different types of produced artifacts (peer presentations, multiple-choice questions, essays, hand-outs, web resources such as wikis), and their persistence (stored persistently for a long time, or alternatively, transient). The survey also highlighted such benefits of CSP as i) CSP fosters learning of the course contents; and ii) promotes the development of a wide range of skills such as research, communication, interdependence, individual accountability, and interpersonal skills [25].

The CSP literature most commonly reports on the effect of CSP activities on the development of generic skills and social interaction rather than on significant increase in the understanding of course content. Only rare quantitative studies assess whether student understanding of the content improved as a result of their contribution to CSP activity. Moreover, Hamer et al [25] admit that they found very little literature addressing the quality of produced student artifacts. Therefore, they argue that the course assessment needs to be aligned with the instructor's expectations of the students: "if the instructor desires high-quality student contributions (so as to ensure that these contributions are genuinely assisting the learning of other students), then the quality of these contributions must be assessed" [25]. Since assessment is of fundamental interest to both students and teachers independent of pedagogy, different kinds of assessment are required for effective application of CSP, which is also true with regards to the SFC concept.

\section{The Self Aspect of the Self-Flipped Classroom (SFC) CONCEPT}

The self aspect of the self-flipped classroom (SFC) concept is based on pedagogical theories on learning through making [4] and stands for the idea that the students should generate the learning material. Figure 1 depicts components of the SFC concept; in this section we will take a deeper look into aspects of the learning material. It is worth noting that one practical aspect behind the development was to be able to reuse student-generated content in the teaching of other cohorts of students, as an alternative method for creation of learning materials for flipped classroom teaching.

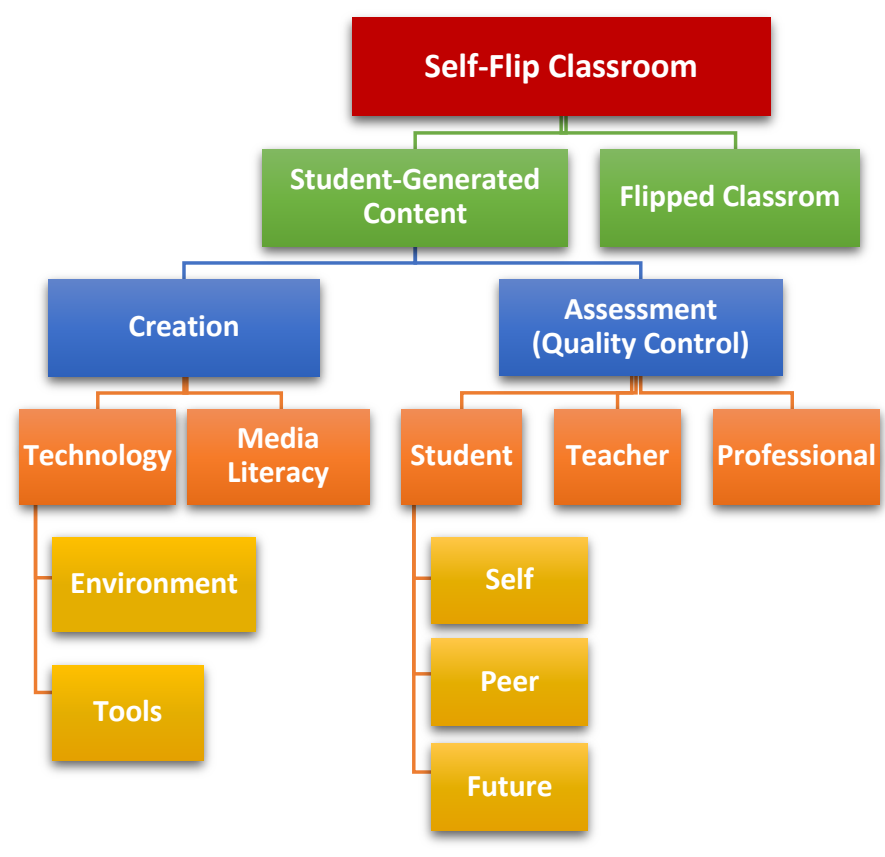

Fig. 1. Components of the Self-Flipped Classroom Concept. 
There are two main aspects related to the student-generated content (artifacts), where one is the learning that occurs as the students generate the content and the other is the fact that other students should learn from the generated material. The latter aspect illustrates the need for generating high quality artifacts, whereas the quality of the artifacts is secondary to the learning of those students who create them in the first place. We will address both of these aspects in presenting the building blocks of SFC illustrated in Figure 1. The creation aspect encompasses such elements as media literacy (the most important skill the students need to be able to create) and technology (the affordances of the modern digitized world and the various specific tools available to facilitate the creation), whereas assessment is an instrument to ensure sufficient quality of created artifacts.

\section{A. Media Literacy}

Media literacy, which could be defined as "the ability of a citizen to access, analyze, and produce information for specific outcomes" [29] is essential for producing high quality learning artifacts. This ability could either be a learning goal by itself or something the students have acquired in earlier courses. The SFC setting is thus an excellent platform for addressing media literacy as a learning goal, since the discussions of content creation and the process students go through when they approach, discuss, design, and create artifacts contribute to the development of their media literacy. Media literacy skills are also crucial for the teacher in order to be able to support the students if the quality of the product is essential for the educational setting.

Media literacy has been discussed and approached by educators in Europe, North America and Australasia for nearly three decades. Many studies, including white papers [30], [31] and national reports [32], [33], were dedicated to this important component of $21 \mathrm{st}$ century life. It has even evolved into a discipline on its own, which is now taught in elementary and secondary schools [34]. Gilmor reasons, "being literate in today's world means more than just smarter consumption, however actively you do that. Being literate is also about creating, contributing and collaborating" $[35, \mathrm{p}$. 60]. This perspective resonates with the theory of constructionism, discussed above, with a particular emphasis on that the best learning happens through application of the knowledge in the form of learning artifact creation [8], [36].

It should be noted that the importance of media literacy decreases in educational settings where there is less focus on the quality of learning artifacts.

\section{B. Technology}

Technology is another potentially central issue in an SFC based educational setting. This is similar to the media literacy aspect expanded on above as it influences the quality of learning artifacts. As with media literacy, mastering technology for artifact generation can be considered a learning goal by itself. From our own practice and the studied literature presenting implementation of student-content creation into curriculum, we have identified a set of different types of digital products that students can potentially produce as part of their learning and which in turn could be reused by the instructor as teaching material for other students. Below is a list summarizing these findings:
- Video tutorial - a 'How To' video which shows and explains steps necessary to solve a problem or to produce a particular result [19], [37]-[39].

- Video presentation - an instructional video which presents results of a research project done by students (in a group or individually) [38], [40].

- Multiple-choice question - a question on the course material (pre-class reading or video lectures) with several plausible answers [16], [22].

- Problem solving activities - a problem is an issue that is investigated, discussed and analyzed, which could take the form of a puzzle, a scenario, a story, a dilemma or a case study [41].

- Blog post - a short reflective essay about activities exercised during teaching sessions addressed to the student's peers [13].

- Animation - same as video tutorials and presentations but created in a form of digital graphic or stopmotion [8], [42].

- Podcast - an audio recording which can be played on a computer or any portable player. Podcasts originally were only in audio format, however recently they more often include both audio and visual format (ex. screencasts) [43].

- Editable wiki-page - encyclopedic pages that enable learners to collaborate, share ideas, and curate content by editing the document together [13], [14].

- Vignette - a short interactive summary of video lectures (screencasts/recaps) covering the critical concepts of the topic [17].

- Digital game - a desktop or mobile game that aims to introduce teaching content in an entertaining manner: in order to win the game the learner have to master certain skills [18], [44].

Tools that support these techniques of content creation could be classified into following categories: digital, collaborative, social, easy to use, mobile and fast changing.

\section{Assessment}

Assessment can come in many different formats in educational settings based on the SFC concept. It can be closely coupled with the quality of learning artifacts and assessed by student peers, teachers or experts. When a produced artifact is used extensively it is essential that it is of high quality and should for instance be free from misconceptions. Teachers and/or experts are likely needed in the loop from creation to distribution for this condition to be fulfilled. This aspect is similar to the various forms of student contributing pedagogy (CSP) [25] presented above, especially when strict formalities are to be applied to the assessment.

As highlighted in [38], in the assessment of the studentgenerated artifacts it is extremely important to ensure that marks are attached to the correctness of the presented concepts, rather than to the quality of the materials itself. For instance, when students create a video tutorial, the biggest portion of mark should be given for accuracy in explaining the steps required to achieve a certain task in the tutorial, and 
the criteria for the video communication should be solely concerned with the effective use of the video medium (e.g. shots framing, pace of storyline), rather than the quality of the production itself.

Also, assessment is particularly delicate when it is done by student peers. It is imperative that instructors build an environment of trust where all students will value the contributions of others, especially if they passed the quality control check. Falkner and Falkner [45] suggest that in successful CSP, students have to not only skillfully assess and value the contributions of their peers, but must also develop the required skills to evaluate their own contributions for "their potential to encourage learning by other students". Therefore, students will aim at constructing their artifacts with significant value for others.

Although the issue of trustworthiness is a recurring theme throughout the literature on CSP, we have not been able to find its evaluation. Interestingly, while Hoban [42] and Engin [37] warn about the danger of scientific misconception and a lack of trust from learning students in the student-generated artifacts, Granmo and Bengtsson [46] argue that studentgenerated materials are more credential and user-oriented.

Different educational settings based on the SFC concept can vary considerably with regards to assessment issues. For instance, settings aimed at mainly using the artifact generation as a step towards being able to understand and discuss some learning objective place little value on assessing the actual artifact.

\section{Three SElF-FlipPed ClassRoom BASED EDUCATIONAL SETTINGS}

The self-flipped classroom concept has been developed at Newcastle University, UK, [3] and has been used there in order to enhance student learning and support acquisition of a wide range of $21^{\text {st }}$ century skills, including media literacy. Details of this setting are described in subsection A. Two more educational settings, from Uppsala University, Sweden, have been adjusted to incorporate SFC concept. We report the experiences from these settings in subsections B and C. In addition, in the subsection $\mathrm{D}$ we describe coursework assessment principles and research methods for the course evaluations that were common to all three of the presented settings.

\section{A. SFC-Based Educational Setting at Newcastle University}

In Newcastle University the SFC approach has been applied to a $3^{\text {rd }}$ year undergraduate module on Ubiquitous computing ("Ubicomp") for three consecutive academic years (from 2015-16 to 2017-18) so far. The learning objectives of the module are to introduce students to the field of Ubicomp and develop practical skills in building interactions using a prototyping toolkit (Raspberry Pi). The module is delivered in a flipped classroom format. The class comprised 34 students in the year 2015-16 and 48 students in each of the years of 2016-17 and 2017-18.

As part of module assignment students create three short video tutorials of their practical sessions, explaining how to program Raspberry $\mathrm{Pi}$ and the Grove $\mathrm{Pi}$ kit in different scenarios, for example, how to process digital or analogue data or how to combine inputs and outputs. See Figure 2 for screenshots of an example. This part weighed $30 \%$ of the student total mark for the course.
In 2016-17 and 2017-18 another $40 \%$ of the module mark was given for writing answers to 'big questions' discussing Ubicomp issues (e.g. "Will privacy matter in a Ubicomp future?" or "Have toolkits such as $\mathrm{Pi}$ and Arduino democratized Ubicomp?") in a form of blog-posts. The rest of the course mark was awarded for weekly quizzes and participation in both online and in-class active learning activities (such as debates, small-scale research projects, presentations, prototyping, etc.)

The introduction of the SFC was gradual with only video tutorials created during the first year, and with videos and blog-posts during the second and the third years. The plan is to accumulate a sufficient amount of ready-to-reuse materials and incorporate them into the curriculum for future iteration of the module. So far, the artifacts were mostly used as examples of good and bad coursework from the previous year. However, also using simpler examples of the previously produced video tutorials to supplement practical sessions, allowed students to create slightly more complex tutorials: from basic turning on and off an LED to a scenario where an LED is connected to a proximity sensor or similar.

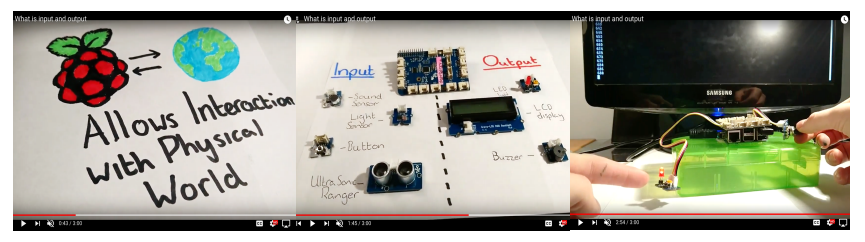

Fig. 2. Screenshots from tutorial about input and output of Raspberry Pi, created for "Ubicomp" 2016-17 module.

\section{B. SFC-Based Educational Setting 1 at Uppsala University}

SFC-based setting 1 at Uppsala University is the "IT and Society" module offered to students coming from different university programs. Most of the students in the year 201718 come from master programs of computer science and the IT program. Some students also come from a partner US university where they study at engineering programs such as electrical engineering. To sum up, the students come from very diverse cultural backgrounds and from different universities, and the course is a globally distributed project course.

The course aims at providing students with knowledge and ability concerning the interplay between user, technology and organizations based on relevant areas of humancomputer interaction. A large project in collaboration with health care is the setting of the course, and each year the students are given a real problem to investigate. In the year 2017-18 the problem to address was the use of tracking equipment in health care, and the students had organized their work in several teams addressing this issue from the perspectives of technology, ethics, privacy, etc. In order to pass the course, the students needed to show that they can handle, validate and criticize solutions to IT-related problems from different perspectives such as ethics, sustainable development, work environment, economy and usefulness.

The course is based on the concept of Open-Ended Group projects that has been iteratively developed and refined during the last 15 years. This concept includes a focus on development of professional competencies in order to address complex and multifaceted problems in software engineering. Scaffolding activities during the project course include 
individual meetings, team meetings, reflection assignments and a writing assignment.

In the course each student also writes a learning agreement that is discussed in meetings with faculty. These learning agreements include a description of which three graduate attributes to focus on during the course. We have used the graduate attributes developed and presented by Curtin University, Australia, in the course. In the learning agreements the students present the three areas that they want to develop and also what they are planning to do to develop the competence including what resources they are using in order to develop their skills. These resources are of different kinds depending on the focus of the learning agreement, but often they include interview templates, TED-talks, online courses or articles of different kinds. Often the students find it very difficult to write these learning agreements, and to find good resources to use in the development.

In 2016-17 we launched a Wikipedia system to scaffold this activity. The students are required to record the resources used for the development of the three professional competencies in Wikipedia including a description of how to use it, and a rating of the usefulness of the resource, which then constitutes an artifact that is possible to reuse by next year's students as the self part of the flipped learning model.

\section{SFC-Based Educational Setting 2 at Uppsala University}

SFC-based setting 2 in Uppsala is a course on how to work with complex IT systems in large organizations. The learning outcomes of the course are related to development, procurement, implementation and maintenance of complex IT systems in large organizations. The readings of the course include novel approaches to software engineering problems and scientific papers in the area. It is mandatory to attend five out of seven lectures in the course, and the coursework is a combination of both individual and group assignments.

In this course the students make short video clips to capture interviews they conduct with key persons in industry. See Figure 3 for screenshots of an example. Each interviewee has to meet a group of three students who have prepared a set of questions related to the work of the interviewee. The video clips are shared among the students and used as a base for discussion regarding some of the key learning goals in the course. Finally, workshops with students are carried out that are based on the learning theory of constructive controversy [47] and the technique affinity diagram to ensure peer learning.

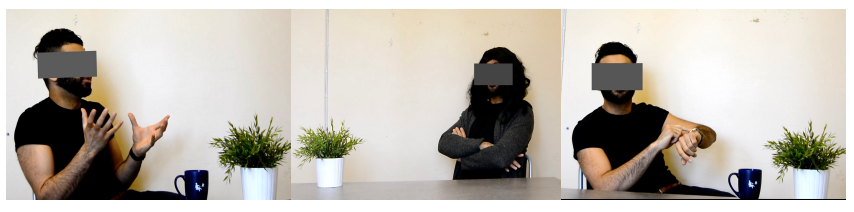

Fig. 3. Screenshots from video interview, created for "Complex IT systems in large organizations" 2017-18 module.

\section{Methods of evaluation}

\section{1) Assessment of student artifacts}

In all of our case studies the student created artifacts were part of the assessed coursework. However, none of them individually contributed more than $40 \%$ toward the overall mark. The other parts of the assessed work included tasks such as quizzes, hackathons, final individual reflections, etc.
This allowed to demonstrate a variety of students' skills, and those students who felt less comfortable with creative tasks were not disadvantaged. Most importantly, the assessment of the artifacts was tuned to the demonstration of the subject learning rather than production quality of the artifacts themselves.

The assessment criteria for video-based coursework were weighted towards the quality of the presented technical skills and understanding of required concepts for working with Raspberry Pi ("Ubicomp"), and the clear demonstration of understanding of the principles and rules for working in large IT organizations ("Complex IT systems in large organizations"). The videography characteristics such as clarity of the image and sound, pace of the presented information, use of captions and graphics were assessed only as a medium to deliver the technical information.

As for the text-based coursework, the focus of assessment was on fitting of the work to the purpose: construction of a persuasive argument to answer a question ("Ubicomp"), or creation of a useful resource to learn about selected professional competencies ("IT and society"). The marks were weighted towards relevance of the artifact to both the student who created it and the others who would use it later. Another significant component of the mark was a good use of a wide range of media and other references (including academic literature).

In general, the instructors on all of our case studies were impressed with the quality of the created artifacts. Many students have demonstrated creativity and other nontechnical skills such as acting, drawing, high quality video editing, creative writing, etc. Some students went extra mile by creating prototypes for their videos which further indicates their engagement and improved motivation in the course.

\section{2) Evaluation of the modules}

To understand the student acceptance of and attitudes toward the SFC teaching and learning approach we collected a range of qualitative data sets for each of our case study. Our research question was the same in all cases:

What are the student attitude to and experiences of the new teaching and learning method (the self-flipped classroom)?

The data collection methods included: student end of the course evaluation and general feedback about the course; our classroom observations, semi-structured interviews and questionnaires with a mix of closed- and open-ended questions. In particular, for the "Ubicomp" 2015-16 we collected 8 interviews and 10 survey responses from the total 34 students; for the "Ubicomp" 2016-17 9 interviews and for the "Ubicomp" 2017-18 19 survey responses were collected from 48-student cohorts. In the case of "IT and Society" each student $(\mathrm{n}=15)$ had an individual interview-style meeting with a faculty member to discuss their reflection on the course. In the "Complex IT systems" course 9 students out of 46-student cohort filled in a survey questionnaire.

The collected data was analyzed using inductive content analysis. The main result of this analysis is the identification and conceptualization of the four student roles that are key to the SFC. The roles are presented in detail in the section V.

In addition to the qualitative data, separate sets of quantitative data were collected from the used tools (e.g. module website, video creation application, tool for reflective $\operatorname{logs}$ ). This aimed at investigating specific aspects of the 
applied innovative teaching methods. This data was analyzed separately and the first results were published in [39].

\section{ObSERVATION ANd Discussion of StUdent Roles}

Through our work with the SFC concept, comprising teaching experience, classroom observations, and numerous form of the student feedback, we have identified different roles that the students take on in these courses. These roles are indicators for students gaining the lifelong learning skills associated with each role. In this section we will relate to the case studies and to the SFC model that was presented in section III. The presented findings are illustrated with the anonymized quotes form student interviews and responses to questionnaires from all three of the presented SFC settings.

\section{A. Students as creators:}

As highlighted in the theoretical background section of this paper, in a contribution-oriented pedagogical approach content creation by the students is just as important as content consumption [25], [45], [48]. Yet, today students are still unused to be responsible for gathering or creation of the learning materials intended to be studied by their peers or future students. Our findings show that students have a mixed attitude towards artifact creation, especially when it comes to non-traditional types of the coursework, such as video in a computer science module. Some feel that there is too much focus on the creative part in the courses, and do not really see the connection to the learning of the topic. One student from the SFC-based setting 2 at Uppsala University gives this comment when asked "What can be improved in the course":

"The group and individual work isn't focused on the course contents but rather on how to conduct an interview, how to create a movie, how to write a report, not about complex IT systems in large organizations."

On the other hand, students from "Ubicomp" 2017-18 said that they liked the "idea of creating learning materials for someone else as part of their own learning": $29.4 \%(n=5)$ strongly agreed and $41.2 \%(n=7)$ agreed with this statement; only $11 \%(n=2)$ of the respondents disagreed with this statement. In addition, they showed their preference for multimedia materials creation. Students in general, despite some having difficulties with initial understanding of what is exactly required from them, accepted the idea of video making very positively. These two quotes illustrate this:

"I like the idea; the concept was good. It was like: "Hey, here's the thing we did. Hey, it turned on. Hey, its flashing. Hey, it's all singing, it's all dancing, look what we made this Pi do!" That's cool, I love that idea! ",

"Videos were good, it's a different way. I have never done it before and it was good."

One can also conclude that there are different approaches to the process of creation where some students spend a lot of time preparing the artifact by reading up on related work, making a prototype, mastering a video editing software, etc., whereas others do as little as possible. Some students from SFC-2 at Uppsala University filling in the anonymous survey described that they had spent too much time on the course compared to the course credits gained, whereas others described that they had hardly spent any time at all.

When asked about what information sources they used in the creation process, students from Uppsala SFC-based setting 1 answered that they had used a very large variety of sources such as:

"Course literature, Wikipedia, YouTube, lectures, some other literature."

and

"Lectures, teachers, Slack, external people at the hospital."

Finally, the quality of the created materials varies and this of course affects the learning of the creators and their peers.

\section{B. Students as collaborators}

As argued by Gillmor [35], becoming a creator today means becoming a collaborator too, as most of the contemporary tools for creation are inherently collaborative. Besides, today one of the first items on the agenda of a newly hired graduate is learning how to effectively collaborate within the team. So, when we are equipping the students with professional lifelong learning skills an important part should be devoted to the skill of collaboration. Equally, the ability to collaborate during artifact creation is an important factor in SFC settings. It can be seen as a learning objective in itself.

However, it is worth noting that students also have to learn how to work individually, and some actually prefer that. So, a combination of collaborative and individual tasks for SFC coursework has been found to be the most preferable. After the first iteration of the SFC module in Newcastle University student attitude towards group work on their coursework was mixed. Some were complaining:

"I didn't like that it was literally all team work, some individual work would have been nice."

While other students were saying:

"I enjoy group work, I think it's a good idea, in a good way to hear other people's ideas and other people's opinions."

To mitigate this issue further iterations of the module were designed the way that part of the coursework was a team-work (first part of video creation and initial discussions of the big questions) whereas the rest (preparation of the final videos and the blog-post answering big questions) was individual work. That allowed to keep the collaborative spirit in the class while the course assessment was based on the students' individual submissions.

When asked to what degree the group work has contributed to the learning in Uppsala SFC-based setting 2 all 9 students agreed or completely agreed that the group work had contributed significantly; there were no students who disagreed or completely disagreed.

\section{Students as communicators}

One specific part of the collaboration and peer-learning is the ability to function as a communicator. According to Hobbs [30], through creation of meaningful and accurate messages "for real audiences, using digital tools, images, language, sound and interactivity" students will not only develop their knowledge and skills but also discover the power of being effective communicators. This is particularly interesting in terms of learning; compare, for instance, with the common claim that "I didn't learn the stuff until I had to teach it!". 
When looking into how students communicate their knowledge to other students through the creation of the artifacts and how they view sharing with students in future course instances, one can see that this is an aspect that was much appreciated by many students, as in this quote from "Complex IT systems in large organizations" student:

"The course gives the chance to develop skills that would otherwise only be possible on self-help bases such as communication, leadership skills, etc."

Similarly, 63\% $(\mathrm{n}=12)$ of survey respondents from "Ubicomp" 2017-18 said they think types of coursework that require multimedia creation (e.g. video or creative text) are helpful to develop skills that will be useful in their future careers.

In addition, our study of media literacy skills acquisition [39] illustrates how students who create multimedia materials develop skills which help them to become successful communicators. One of the students from "Ubicomp" 2015-16 commented:

"I learned how to create a concise and informational video, which can be used to demonstrate my knowledge in a more 'interesting' way."

\section{Students as learners}

The ultimate goal of the self-flipped classroom, as of any other pedagogy, is that students learn. The above roles are strongly influential in how well the learning takes place. One should note that not all students appreciate active learning approaches and learning from peers as they are not used to this in their learning environment. When asked to comment a statement: "We have been given the opportunity to be active during the course" in a survey sent to SFC-Based setting 2 at Uppsala University one of the students said:

\section{"To a too high degree - there's barely any teaching at all."}

In contrast, other students did see the value in the new approach. For example, when students from "Ubicomp" 2017-18 were asked to agree or disagree with the statement: "I think this coursework (video and blog-post creation) has helped me to learn the course material better" $35.3 \%(n=6)$ agreed with it and $52.9 \%(\mathrm{n}=9)$ agreed strongly; only $11.8 \%$ $(\mathrm{n}=2)$ have disagreed. One student commented:

"It did force me to gain an understanding of the task thoroughly so that I knew I had the knowledge to explain precisely what to do."

When the same students were asked about their preferences for the purposes of using materials and resources, that other students produced previously, 63\% $(n=12)$ of respondents preferred to use those materials to learn the course content and $73.6 \%(n=14)$ preferred to learn how to create a similar course work. One student said:

"Having these resources available was useful to see how to and how not to do things and to clarify the topic area".

\section{IMPLICATIONS}

In this section we present some implications related to teaching using the self-flipped classroom concept:
- Be explicit about the pedagogical underpinnings of the self-flipped classroom and be prepared to answer questions related to this new way of teaching.

- Students might find it difficult to appreciate the learning experience provided through the self-flipped classroom, and some students appreciate traditional lectures where they are passive listeners.

- Discuss the different roles taken by students in the selfflipped classroom and what kind of learning these result in.

- Be prepared to scaffold student artifact creation. Some students who have not been engaged in content creation before do not always easily understand what is expected from them.

- Be prepared to work more with course administration in the self-flipped course setting than in a traditional course. Time spent on preparing lectures in other courses will be spent on preparing and administering the learning experience of the students.

\section{FUTURE WORK}

Student perceptions of the learning experiences need to be explored further in relation to the self-flipped classroom concept. We will conduct several studies related to this in the future. In particular, Survey Study I: a questionnaire instrument will be developed and distributed to a wider audience. The focus of the survey will be on increasing the understanding of student attitudes towards different aspects of the self-flipped classroom concept. Survey Study II: a second survey will be distributed to the students in SFCbased setting 2 at University B. This survey will be focusing on the learning experience of creating films as learning material for others. Interview Study: A semi-structured interview study will be carried out in both our universities where questions will be focusing on the learning experience of the students. Moreover, we are working on the development of strategy to investigate the experiences of students who learn from the student-generated materials.

Other directions for our future work include: a) development of a comprehensive "toolbox" of assessment methods for the acquisition of lifelong learning and professional skills; b) evaluation of quality of the studentcreated artifacts from various perspectives; c) investigation of effectiveness of the SFC approach in comparison to the traditional teaching and learning methods.

\section{CONCLUSION}

In this paper we presented an innovative pedagogy designed to improve acquisition of lifelong learning skills for science and technology students. The pedagogy, called selfflipped classroom, is illustrated by describing our practical experiences of its implementation in three educational settings from two universities in the UK and Sweden. Our main findings articulate four student roles identified in a selfflipped classroom scenario: creators, collaborators, communicators, and learners. These roles are instrumental in helping the students to develop the corresponding lifelong learning and professional skills, which are most sought-after in modern world. 


\section{REFERENCES}

[1] J. L. Bishop and M. A. Verleger, "The Flipped Classroom: A Survey of the Research," in Proccedings of the Annual Conference of the American Society for Engineering Education, 2013.

[2] L. Jones, The Student-Centered Classroom. New York: Cambridge University Press, 2007.

[3] A. Vasilchenko, "Self-Flipped Teaching \& Learning for STEM in Higher Education," in Adjunct Proceedings of 15th European Conference on Computer-Supported Cooperative Work, 2017, pp. 14.

[4] S. Papert, Mindstorms: Children, computers, and powerful ideas. New York: Basic Books, Inc., Publishers, 1980.

[5] J. Dewey, Experience and Education. New York: MacMillan, 1938.

[6] J. Piaget, Six psychological studies. New York: Random House, 1967.

[7] E. Ackermann, "Piaget's Constructivism, Papert's Constructionism: What's the difference," in Constructivism: Uses and Perspectives in Education, 2001, vol. 5, no. 3, pp. 1-11.

[8] G. Hoban, W. Nielsen, and C. Carceller, "Articulating constructionism: Learning science though designing and making 'slowmations,"” ASCILITE, pp. 433-443, 2010.

[9] Y. B. Kafai, "Constructionism," in The Cambridge Handbook of the Learning Sciences, R. K. Sawyer, Ed. New York: Cambridge University Press, 2006, pp. 35-46.

[10] S. Vossoughi and B. Bevan, "Making and Tinkering : A Review of the Literature," National research Council Committee on Out of School Time STEM. pp. 1-55, 2014.

[11] P. M. Rodriguez, C. Frey, K. Dawson, F. Liu, and A. D. Ritzhaupt, "Examining Student Digital Artifacts During a Year-Long Technology Integration Initiative," Comput. Sch., vol. 29, no. 4, pp. 355-374, 2012.

[12] C. Mcloughlin and M. J. W. Lee, "The Three P's of Pedagogy for the Networked Society," Int. J. Teach. Learn. High. Educ., vol. 20, no. 1, pp. 10-27, 2008.

[13] S. Wheeler, P. Yeomans, and D. Wheeler, "The good, the bad and the wiki: Evaluating student-generated content for collaborative learning," Br. J. Educ. Technol., vol. 39, no. 6, pp. 987-995, 2008.

[14] New Media Consortium, "Horizon Report 2007," 2007. [Online]. Available: http://www.nmc.org/pdf/2007_Horizon_Report.pdf. [Accessed: 23-Jun-2016].

[15] M. Gleason, "Better Communication in Large Courses," Coll. Teach., vol. 34, no. 1, pp. 20-24, Feb. 1986.

[16] M. R. Fellenz, "Using assessment to support higher level learning: the multiple choice item development assignment," Assess. Eval. High. Educ., vol. 29, no. 6, pp. 703-719, Dec. 2004.

[17] D. Read and S. Lancaster, "Unlocking video: 24/7 learning for the iPod generation," Educ. Chem., no. July, 2012.

[18] Y. B. Kafai, "Playing and Making Games for Learning: Instructionist and Constructionist Perspectives for Game Studies," Games Cult., vol. 1 , no. 1 , pp. 36-40, 2006.

[19] K. Gravett, "Using online video to promote database searching skills: the creation of a virtual tutorial for Health and Social Care students," J. Inf. Lit., vol. 4, no. 1, pp. 66-71, 2010.

[20] S. P. Bates, R. K. Galloway, and K. L. McBride, "Student-generated content: using PeerWise to enhance engagement and outcomes in introductory physics courses," in Physics Education Research Conference, 2011.

[21] S. P. Bates, R. K. Galloway, J. Riise, and D. Homer, "Assessing the quality of a student-generated question repository," Phys. Rev. Spec. Top. - Phys. Educ. Res., vol. 10, no. 2, pp. 1-11, 2014.

[22] J. Hardy, S. P. Bates, M. M. Casey, K. W. Galloway, R. Galloway, A. E. Kay, P. Kirsop, and H. A. McQueen, "Student-Generated Content: Enhancing learning through sharing multiple-choice questions," Int. J. Sci. Educ., vol. 36, no. 13, pp. 2180-2194, 2014.

[23] B. Collis and J. Moonen, An On-Going Journey : Technology as a Learning Workbench. 2005.

[24] J. Hamer, H. C. Purchase, A. Luxton-Reilly, and J. Sheard, "Tools for 'contributing student learning," ACM Inroads, vol. 2, no. 2, pp. 78$91,2011$.

[25] J. Hamer, Q. Cutts, J. Jackova, A. Luxton-Reilly, R. McMartney, H.
Purchase, C. Riedesel, M. Saeli, K. Sanders, and J. Sheard, "Contributing Student Pedagogy," in inroads - SIGCSE Bulletin, 2008, vol. 40, no. 4, pp. 194-212.

[26] M. Ben-Ari, "Constructivism in computer science education," $A C M$ SIGCSE Bull., vol. 30, no. 1, pp. 257-261, Mar. 1998.

[27] L. Vygotsky, Mind in society: The development of higher psychological processes. Cambridge, Massachusetts: Harvard university press, 1978.

[28] Å. Cajander, M. Daniels, and R. McDermott, "On valuing peers: theories of learning and intercultural competence," Comput. Sci. Educ., vol. 22, no. 4, pp. 319-342, 2012.

[29] P. Aufderheide, "Media Literacy: A Report of the National Leadership Conference on Media Literacy," 1993.

[30] R. Hobbs, Digital and Media Literacy: A Plan of Action. Washington, D.C.: The Aspen Institute, 2010.

[31] H. Jenkins, R. Purushotma, M. Weigel, K. Clinton, and A. J. Robison., Confronting the challenges of participatory culture: Media education for the 21st century. MIT Press, 2009.

[32] S. Krucsay, Educating for the Media and the Digital Age, no. April. Vienna: the Austrian Federal Ministry of Education and Cultural Affairs, Department for Media Education, 1999.

[33] E. Thoman, "Media Literacy - A National Priority for a Changing World," Am. Behav. Sci., vol. 48, no. 1, pp. 18-29, 2004.

[34] T. Jolls and C. Wilson, "The Core Concepts: Fundamental to Media Literacy Yesterday, Today and Tomorrow," J. Media Lit. Educ., vol. 6, no. 62, pp. 68-78, 2014.

[35] D. Gillmor, Mediactive. Creative Commons, 2010.

[36] S. Papert and I. Harel, "Situating Constructionism," in Constructionism, Ablex Publishing Corporation, 1991.

[37] M. Engin, "Extending the flipped classroom model: Developing second language writing skills through student-created digital videos.," J. Scholarsh. Teach. Learn., vol. 14, no. 5, pp. 12-26, 2014.

[38] A. Vasilchenko, A. Wilde, S. Snow, M. Balaam, and M. Devlin, "Video coursework," in Proceedings of the 2018 International Conference on Advanced Visual Interfaces - AVI '18, 2018, pp. 1-3.

[39] A. Vasilchenko, D. P. Green, H. Qarabash, A. Preston, T. Bartindale, and M. Balaam, "Media Literacy as a By-Product of Collaborative Video Production by CS Students," in 22nd Annual Conference on Innovation and Technology in Computer Science Education, 2017.

[40] A. Sahin and N. Top, "STEM Students on the Stage (SOS): Promoting Student Voice and Choice in STEM Education Through an Interdisciplinary, Standards-focused, Project Based Learning Approach," J. STEM Educ., no. September, pp. 24-34, 2015.

[41] T. Barrett, D. Cashman, and S. Moore, "Designing problems and triggers in different media," in New approaches to problem-based learning revitalising your practice in higher education, T. Barrett and S. Moore, Eds. New York, NY: Routledge, 2011, pp. 18-35.

[42] G. Hoban, D. C. Macdonald, and B. Ferry, "Improving Preservice Teachers' Science Knowledge By Creating, Reviewing And Publishing Slowmations To TeacherTube," in Society for Information Technology \& Teacher Education International Conference, 2009, pp. 3133-3140.

[43] M. Frydenberg, "Principles and Pedagogy: The Two Ps of Podcasting in the Information Technology Classroom," Inf. Syst. Educ. J., vol. 6, no. 6, pp. 1-11, 2008.

[44] M. Prensky, "Digital Natives, Digital Immigrants Part 1," Horiz., vol. 9, no. 5, pp. 1-6, 2001.

[45] K. Falkner and N. J. Falkner, "Supporting and Structuring 'Contributing Student Pedagogy' in Computer Science Curricula," Comput. Sci. Educ., vol. 22, no. 4, pp. 413-443, 2012.

[46] M. Granmo and F. Bengtsson, "Teaching Anatomy in the Multimedia World - Using Digital Tools for Progressive Learning over Time," Creat. Educ., vol. 6, no. June, pp. 1193-1200, 2015.

[47] M. Daniels and Å. Cajander, "Constructive Controversy as a Way to Create 'True Collaboration' in an Open Ended Group Project Setting," in Proceedings of the Twelfth Australasian Conference on Computing Education, 2010, pp. 73-78.

[48] B. Collis and J. Copsey, "The contributing student: A blend of pedagogy and technology.," 2005. 